УДК 616.25-003.219-055.2-039.19-07-089.87

DOI 10.11603/24116-4944.2017.2.7795

๑В. В. Ткаліч, В. Г. Гетьман, В. В. Соколов, Д. В. Мясніков, Ю. В. Неділя,

В. І. Галак, Н. П. Бабій, В. О. Ткаліч, В. В. Біла

Київсъка місъка клінічна лікарня № 17

Перинатальний центр м. Києва

\title{
СПОНТАННИЙ ПНЕВМОТОРАКС ПІД ЧАС ВАГІТНОСТІ. ОСНОВНІ АСПЕКТИ ДІАГНОСТИКИ, ТАКТИКИ ЛІКУВАННЯ ПНЕВМОТОРАКСУ І ВЕДЕННЯ ПОЛОГІВ
}

\begin{abstract}
Мета дослідження - вивчити особливості діагностики та лікування пневмотораксу під час вагітності й подальшого розродження.

Матеріали та методи. Першовагітна віком 32 роки перебувала на лікуванні та спостереженні в КМКЛ № 17 і 7-му пологовому будинку м. Києва з 30.03.11 до 20.10.11. Їй проводили повний клініко-діагностичний комплекс обстежень та лікування відповідно до діючих протоколів.

Результати дослідження та їх обговорення. У статті представлено огляд літератури з питання спонтанного пневмотораксу у вагітних та подано опис клінічного випадку. Узагальнено особливості діагностики, лікування пневмотораксу під час вагітності та ведення пологів у таких хворих. Рентгенівський знімок грудної клітки вагітної є безпечним для плода після 8-го тижня вагітності. Сучасні міні-інвазивні методики хірургічного лікування є методом вибору при лікуванні пневмотораксу у вагітних. Кесарів розтин виконують виключно за акушерськими показаннями. Всебічне дообстеження породіллі в післяпологовому періоді необхідне для встановлення етіології пневмотораксу, який був під час вагітності. Специфічних заходів з профрілактики пневмотораксу дотепер не існує.

Висновки. Пневмоторакс під час вагітності - рідкісне явище і зустрічається в 1 випадку на 10000 пологів. Пневмоторакс у вагітних становить високу загрозу життю матері та плода, що зумовлює актуальність своєчасної діагностики та правильного лікування цього захворювання. Діагностику напруженого пневмотораксу необхідно здійснювати на етапі клінічного обстеження, а лікувальні заходи повинні бути невідкладними та передувати рентгенологічному обстеженню.
\end{abstract}

Ключові слова: пневмоторакс; рецидивуючий пневмоторакс; ускладнення вагітності; допологовий медичний супровід.

СПОНТАННЫЙ ПНЕВМОТОРАКС ВО ВРЕМЯ БЕРЕМЕННОСТИ. ОСНОВНЫЕ АСПЕКТЫ ДИАГНОСТИКИ, ТАКТИКИ ЛЕЧЕНИЯ ПНЕВМОТОРАКСА И ВЕДЕНИЯ РОДОВ

Цель исследования - изучить особенности диагностики и лечения пневмоторакса во время беременности и дальнейшего родоразрешения.

Материалы и методы. Первобеременная в возрасте 32 года находилась на лечении и под наблюдением в КГКБ № 17 и 7-м роддоме г. Киева с 30.03.11 по 20.10.11. Ей проводили полный клинико-диагностический комплекс обследований и лечение соответственно действующим протоколам.

Результаты исследования и их обсуждение. В статье представлен обзор литературы по вопросу спонтанного пневмоторакса у беременных и дано описание клинического случая. Обобщены особенности диагностики, лечения пневмоторакса во время беременности и ведения родов у таких больных. Рентгеновский снимок грудной клетки беременной является безопасным для плода после 8-й недели беременности. Современные мини-инвазивные методики хирургического лечения являются методом выбора при лечении пневмоторакса у беременных. Кесарево сечение выполняется исключительно по акушерским показаниям. Всестороннее дообследование роженицы в послеродовом периоде необходимо для установления этиологии пневмоторакса, который был во время беременности. Специфических мер просрилактики пневмоторакса до сих пор не существует.

Выводы. Пневмоторакс во время беременности - редкое явление и встречается в 1 случае на 10000 родов. Пневмоторакс у беременных составляет высокую угрозу жизни матери и плода, обуславливает актуальность своевременной диагностики и правильного лечения этого заболевания. Диагностика напряженного пневмоторакса должна осуществляться на этапе клинического обследования, а лечебные мероприятия должны быть неотложными и предшествовать рентгенологическому обследованию.

Ключевые слова: пневмоторакс; рецидивирующий пневмоторакс; осложнения беременности; диагностика; дородовая медицинская помощь.

SPONTANEOUS PNEUMOTHORAX DURING PREGNANCY. MAIN ASPECTS OF DIAGNOSTICS, TACTICS OF TREATMENT OF PNEUMOTHORAX AND MANAGEMENT OF BIRTH

The aim of the study - to learn the features of diagnosis and treatment of pneumothorax during pregnancy and further delivery. Materials and Methods. The first-born women at the age of 32 years was on treatment and under supervision in Kyiv City Hospital number 7 and Kyiv Maternity Home number 7 from 30.03.11 to 20.10.11. She underwent a complete clinical diagnostic complex of examinations and treatment according to the current protocols.

Results and Discussion. The article presents a review of the literature on spontaneous pneumothorax in pregnant women and describes a clinical case; overview of the features of diagnosis, treatment of pneumothorax during pregnancy and childbirth in these patients. An X-ray of a pregnant woman's chest is safe for the fetus after the 8th week of pregnancy. Modern minimally invasive methods of surgical treatment is the method of choice in the treatment of pneumothorax in pregnant women. Cesarean section is performed exclusively on obstetric indications. Comprehensive post-examination of the parturient child in the postpartum period is 
necessary to establish the etiology of pneumothorax, which was during pregnancy. Specific measures to prevent pneumothorax still do not exist.

Conclusions. Pneumothorax during pregnancy is a rare phenomenon and occurs in 1 case per 10.000 births. Pneumothorax in pregnant women is a high threat to the life of the mother and fetus, determines the urgency of timely diagnosis and proper treatment of this disease. Diagnosis of intense pneumothorax should be carried out at the stage of clinical examination, and medical measures should be urgent and preceded by an X-ray examination.

Key words: pneumothorax; recurrent pneumothorax; complications of pregnancy; prenatal care.

ВстУП. Пневмоторакс під час вагітності - рідкісне явище і зустрічається в 1 випадку на 10000 пологів [3]. Незважаючи на це, актуальність питання зумовлюється високою ймовірністю загрози життю матері та плода.

Загалом ризик рецидиву пневмотораксу після першого епізоду впродовж перших 4 років складає 54 \% [3]. У свою чергу, рецидив у вагітних, порівняно з невагітними жінками, трапляється частіше - 44 і 30 \% відповідно [4].

У доступних нам вітчизняних літературних джерелах не виявлено жодних даних стосовно випадків пневмотораксу у вагітних.

У світовій фраховій літературі описано 79 випадків пневмотораксу у вагітних за період з 1948 до 2013 р. [1]

МЕТА ДОСЛІДЖЕННЯ - вИвчити особливості діагностики та лікування пневмотораксу під час вагітності й подальшого розродження.

МАТЕРІАЛИ ТА МЕТОДИ. Першовагітна віком 32 роки перебувала на лікуванні та спостереженні в КМКЛ № $17 \mathrm{i}$ 7-му пологовому будинку м. Києва з 30.03.11 до 20.10.11. їй проводили повний клініко-діагностичний комплекс обстежень та лікування відповідно до діючих протоколів.

РЕЗУЛЬТАТИ ДОСЛІДЖЕННЯ ТА ЇХ ОБГОВОРЕНня. Жінка віком 32 роки, перша вагітність, 38-39 тижнів, звернулася 30.03.11 до пологового будинку № 7 м. Києва зі скаргами на кашель і була направлена на консультацію до відділення політравми КМКЛ № 17 м. Києва. Під час клініко-рентгенологічного обстеження встановлено діагноз «Спонтанний пневмоторакс справа». Хворій виконано торакоскопію (макроскопічних змін на легені та діафррагмі не виявлено), після чого вагітна була госпіталізована для спостереження до відділення інтенсивної терапії, де проводили знеболювальну терапію та інсусляяцію кисню. За результатами повторної консультації акушера-гінеколога: стан шийки матки за Бішоп - 2 бали, на УЗД - серцебиття плода 120-130/хв. Вагітній на 9, 18, 38 тижнях виконували УзД плода - жодних відхилень та патології виявлено не було. Наступного дня хвору переведено до пологового будинку № 7 з діагнозом «Вагітність І, 39-40 тижнів. Пологова діяльність. Дистрес плода. Дренована права плевральна порожнина». Встановлено показання до кесаревого розтину під спінальною анестезією. Операція тривала 45 хв. Народився хлопчик масою 3250 г, довжиною тіла 53 см, 6-8 балів за шкалою Апгар, 3 діагнозом «Ассріксія середнього ступеня, дихальна недостатність I ступеня, високий ризик внутрішньоутробного інфрікування».

Патогістологічний висновок препарату плаценти: маса 590 г, розміри 19×17×25 см. Хоріонічний комплекс не змінений.

Пацієнтці виконано фрібробронхоскопію після народження дитини. 02.04.11 у хворої припинилося скидання повітря в клапан за Бюлау. 04.04.11 рентгенологічно легені розправлені, дренаж видалений. 06.04.11 хвора виписана додому.
13.04.11 хвора повторно звернулась до КМКЛ № 17 з рецидивом пневмотораксу справа. Виконано торакоскопію, при якій не виявлено морфологічних змін на легені та діафррагмі. Дренаж видалений на 5-й день. 19.04.11 виписана додому. Від запропонованого оперативного лікування хвора відмовилась.

12.10.11 о 22:30 хвора звернулась до КМКл № 17 з 3-м епізодом пневмотораксу справа. Скарги на біль у грудній клітці, утруднене дихання, кашель з'явились о 17:00 того ж дня. Виконано плевральну пункцію - евакуйовано $600 \mathrm{~cm}^{3}$ повітря, розрідження + 20 см вод. ст. утримує стійко. 13.10.11 рентгенологічно виявлено пневмоторакс справа. За результатами торакоскопії - на сухожильній частині діасрагми виявлено іїі френестації в кількості 2 шт., розмірами $0,2 \times 0,1$ та 0,1×0,1 см. Хворій запропоновано оперативне лікування, від якого вона категорично відмовилась. 20.10.11 рентгенологічно легені розправлені, плевральний дренаж видалений.

До сьогодні в КМКЛ № 17 пацієнтка не зверталась.

Проблема пневмотораксу у вагітних передбачає висвітлення трьох складових лікувально-діагностичного процесу, таких, як:

1. Клініко-рентгенологічні методи діагностики.

2. Особливості лікування.

3. Особливості ведення пологів.

Клініко-рентгенологічна діагностика пневмотораксу у вагітних.

Клінічна картина пневмотораксу у вагітних не відрізняється від такої в інших груп пацієнтів і включає біль у грудній клітці, задишку і кашель. Наявність задишки впливає на тактику лікування (рівень доказовості D за системою GRADE) [4].

Тяжкі симптоми та ознаки дихальної недостатності можуть бути проявами напруженого пневмотораксу (рівень доказовості D) [4].

Під час фрізикального обстеження можна виявити пальпаторно підшкірну емфізему, аускультативно - послаблення чи відсутність дихальних шумів.

У більшості лікарів існує хибне уявлення про небезпеку виконання рентгенівського знімка грудної клітки вагітній жінці. Поглинена доза рентгенівського опромінення плода під час виконання знімків грудної клітки матері у 2-х проекціях становить $7 \times 10^{-5}$ рад, а за період вагітності максимально допустимою дозою для плода $€ 5$ рад [9]. Отже, вагітній можна зробити 1000 знімків грудної клітки (бажано після 8 тижня) без шкоди для плода. Додаткові методи інструментальної діагностики включають пульсоксиметрію і визначення рівня оксигенації капілярної крові матері $\left(\mathrm{SatO}_{2}\right)$. Якщо SatO 2 вище 92 \% при диханні атмосферним повітрям, то необхідності визначати гази крові немає [4].

Встановлено, що при вагітності потреба матері у кисні зростає на $20 \%$, а під час пологів - на 50 \% [10]. 
Парціальний тиск кисню $\left(\mathrm{PO}_{2}\right)$ у пуповинній вені становить 35-45 мм рт. ст., а тому будь-яке зменшення $\mathrm{SatO}_{2}$ у вагітної може бути потенційно небезпечним або навіть смертельним для плода [11]. В доступних нам літературних джерелах не виявлено діагностичної цінності інших лабораторних методів. Підозра на пневмоторакс у вагітної повинна бути верисрікована рентгенівським знімком грудної клітки на вдиху (рівень доказовості А) [4].

Варто зазначити, що напружений пневмоторакс - це клінічний діагноз, і дренування плевральної порожнини й порятунок життя матері та плода мають передувати виконанню рентгенівського знімка. Клінічні симптоми напруженого пневмотораксу включають біль у грудній клітці, недостатність повітря, респіраторний дистрес, тахікардію, гіпотензію, відсутність дихальних шумів з однієї сторони, розширення вен шиї, ціаноз (пізній симптом) [21].

За даними рентгенографії грудної клітки, пневмоторакс може бути класифікований як малий, великий або напружений. Дотепер, однак, не виявлено чіткої кореляції між об'ємом пневмотораксу та його клінічними проявами [4].

Особливості лікування

Лікування пневмотораксу у вагітних передбачає 2 підходи:

1. Спостереження (з чи без аспірації повітря під час плевральної пункції).

2. Дренування плевральної порожнини в 4-5 міжребер"ї по передній - середній аксилярній лінії [21].

За даними [18], серед 41 випадку пневмотораксу у вагітних у $22 \%$ здійснювали спостереження, у $75 \%$ дренування плевральної порожнини, у 3 \% - торакотомію.

Згідно з рекомендаціями [4], в допологовому періоді проводять спостереження та аспірацію повітря (рівень доказовості C) з подальшим виконанням відеоасистованого торакоскопічного хірургічного лікування (ВАТС) після народження дитини (рівень доказовості D).

Швидкість розсмоктування повітря в плевральній порожнині складає 1,25-2,2 \% об'єму гемітораксу протягом 24 год за умови відсутності додаткового надходження повітря [12-14]. При інсуфрляції кисню хворій швидкість розсмоктування повітря зростає в 4 рази [15].

Вагітність $€$ одним з показань до хірургічного лікування пневмотораксу [4].

На сьогодні поширені методики міні-інвазивного хірургічного лікування вагітних з пневмотораксом (ВАТС,
ВАТС у свідомості під час вагітності [19]). Є публікації про успішні пологи після виконання ВАТС під час вагітності [3]. В доступних нам джерелах не виявлено даних про рецидив пневмотораксу після торакотомії та ВАТС у вагітних [16].

Ведення пологів.

Серед описаного 41 випадку пневмотораксу у вагітних у 56 \% випадків проводились пологи через природні родові шляхи, у $27 \%$ - накладали акушерські щипці, у $12 \%$ - виконували кесарів розтин, у $5 \%$ - дані відсутні. При цьому не відмічено летальних випадків у породіль та описано лише 1 випадок смерті дитини на 11 тижні гестації [3].

В іншому дослідженні, яке включало 46 вагітних 3 пневмотораксом, пологи через природні родові шляхи проводились у 57 \%, акушерські щипці накладали у $20 \%$, кесарів розтин виконували у $18 \%$. У 2-х випадках жінки народжували $з$ плевральним дренажем [16].

Кесарів розтин виконують за акушерськими показаннями [17].

Особливості післяпологового ведення.

Після пологів необхідно провести всебічне дообстеження хворої та встановити етіологію пневмотораксу, який був під час вагітності [20]. Специфрічної профрілактики пневмотораксу не існує.

ВисновКИ. Пневмоторакс у вагітних становить високу загрозу життю матері та плода, що зумовлює актуальність своєчасної діагностики та правильного лікування цього захворювання. Діагностику напруженого пневмотораксу необхідно здійснювати на етапі клінічного обстеження, а лікувальні заходи повинні бути невідкладними та передувати рентгенологічному обстеженню. Рентгенівський знімок грудної клітки вагітної $€$ безпечним для плода після 8-го тижня вагітності. Сучасні міні-інвазивні методики хірургічного лікування повинні розглядатись як метод вибору при лікуванні пневмотораксу у вагітних. Кесарів розтин виконують виключно за акушерськими показаннями.

Всебічне дообстеження породіллі в післяпологовому періоді необхідне для встановлення етіології пневмотораксу, який був під час вагітності, однак специсрічних заходів з профрілактики пневмотораксу дотепер не існує.

ПЕРСПЕКТИВИ ПОДАЛЬШИХ ДОСЛІДЖЕНЬ ПОЛЯгають у верифрікації етіології пневмотораксу у вагітної, міні-інвазивного лікування пневмотораксу під час вагітності.

\section{СПИСОК ЛІТЕРАТУРИ}

1. Should pregnant patient with a recurrent or persistent pneumothorax undergo surgery? / Nnamdi Nwaejike, Ehab Elbur, Kandadai S. Rammohan, Rajesh Shah // Interactive Cardio Vascular and Thoracic Surgery. - 2013. - Vol. 17. P. 988-990

2. Melton L. J. Incidence of spontaneous pneumothorax in Olmsted County, Minnesota: 1950-1974 / L. J. Melton, N. C. G. Hepper, K. P. Offord // Am. Rev. Respir. Dis. -1987. Vol. 29. - P. 1379-1382.

3. Lal A. Pneumothorax and pregnancy / A. Lal, G. Anderson, M. Cowen [et al.] // Chest. - 2007. - Vol. 132. - P. 1044-1048.

4. BTS Pleural Disease Guideline 2010 British Thoracic Society, Thorax, August. - 2010. - Vol. 65.
5. Independent risk factors for cumulative recurrence rate after first spontaneous pneumothorax / H. L. Lippert, O. Lund, S. Blegrad [et al.] // Eur. Respir. - 1991. - Vol. 4. - P. 324331.

6. Spontaneous pneumothorax in chronic obstructive pulmonary disease: complications, treatment and recurrences // Eur. J. Respir. Dis. - 1987. - Vol. 71. - P. 365-371.

7. Bilateral primary spontaneous pneumothoraces postcaesarean section - another reason to avoid general anaesthesia in pregnancy / Aye CYL, D. McKean, A. Dark, S. A. Akinsola // BMJ CaseReports. - 2012. - Vol. 10. - P. 1136.

8. ESTS textbook of thoracic surgery // Medycyna Praktyczna. - 2014. 
9. Toppenberg K. S. Safety of radiographic imaging during pregnancy / K. S. Toppenberg, D. A. Hill, D. P. Miller // Am. Fam. Physician. - 1999. - Vol. 59. - P. 1813-1818.

10. Management of spontaneous pneumothorax during pregnancy: case report and review of the literature / J. T. VanWinter, F. C. Nichols III, P. C. Pairolero [et al.] // Mayo Clinic Proceedings. - 1996. - Vol. 71, No. 3. - P. 249-252.

11. Leontic E. A. Respiratory disease inpregnancy / E. A. Leontic // Medical Clinics of North America. - 1977. Vol. 61, No. 1. - P. 111-128.

12. Flint K. Conservative management of spontaneous pneumothorax / K. Flint, A. H. Al-Hillawi, N. M. Johnson // Lancet. - 1984. - P. 687-688.

13. Kircher L. T. Jr. Spontaneous pneumothorax and its treatment/ L. T. Jr. Kircher, R. L. Swartzel // JAMA. - 1954. - Vol. 155. - P. 24-29.

14. Estimating the rate of reexpansion of spontaneous pneumothorax by a formula derived from computed tomography volumetry studies / A. M. Kelly, J. Loy, A. Y. L. Tsang [et al.] // Emerg. Med. J. - 2006. - Vol. 23. - P. 780-782.

15. Northfield T. C. Oxygen therapy for spontaneous pneumothorax / T. C. Northfield // BMJ. - 1971. - Vol. 4. - P. 86-88.
16. A case of recurrent spontaneous pneumothorax during pregnancy treated with videoassisted thoracoscopic surgery / N. Nwaejike, P. Aldam, T. Pulimood [et al.] // BMJ Case Reports. - 2012. - Vol. 10. - P. 1136.

17. Pneumothorax and pneumomediastinum in pregnancy $/$ S. Sathiyathasan, K. Jeyanthan, G. Furtado, R. Hamid // A Case Report Obstet. Gynecol. Int. - 2009. - Vol. 18.

18. Spontaneous pneumothorax during pregnancy / L. Gorospe, S. Puente, C. Madrid [et al.] // South Med. J. - 2002. - Vol. 95. - P. 555-558.

19. Awake videothoracoscopic surgery for intractable pneumothorax in pregnancy by using a singleportal plus puncture / Ken Onodera, Masafumi Noda, Yoshinori Okadaand, Takashi Kondo // Interactive Cardio Vascular and Thoracic Surgery. 2013. - Vol. 17. - P. 438-440.

20. Spontaneous pneumothorax in the third trimester of pregnancy / Abriel Avital, Ori Galante, Joel Baron, Alexander Smoliakov [et al.] // BMJ Case Rep. - 2009.

21. Atls student course manual: advanced trauma life support 9th ed. Edition American College of Surgeons; September 1, 2012.

\section{REFERENCES}

1. Nwaejike, N., Elbur, E., Rammohan, K., \& Shah, R. (2013). Should pregnant patient with a recurrent or persistent pneumothorax undergo surgery? Interactive Cardio Vascular and Thoracic Surgery, 17, 988-990.

2. Melton, L.J., Hepper, N.C.G., \& Offord, K.P. (1987). Incidence of spontaneous pneumothorax in Olmsted County, Minnesota: 1950-1974. Am. Rev. Respir. Dis., 1379-1382.

3. Lal, A., Anderson, G., \& Cowen, M. (2007). Pneumothorax and pregnancy. Chest, 132, 1044-1048.

4. BTS Pleural Disease Guideline 2010 British Thoracic Society, Thorax, August, 2010, 65.

5. Lippert, H.L., Lund, O., \& Blegrad, S. (1991). Independent risk factors for cumulative recurrencerate after first spontaneous pneumothorax. Eur. Respir. J., 4, 324-331.

6.Videm, V., Pillgram-Larsen, J., Ellingsen, O., Andersen, G., \& Ovrum, E. (1987). Spontaneous pneumothorax in chronic obstructive pulmonary disease: complications, treatment and recurrences. Eur. J. Respir.Dis., 71, 365-371.

7. Aye, C.Y.L., McKean, D., Dark, A., \&Akinsola, S.A. (2012). Bilateral primary spontaneous pneumothoraces post caesarean section - another reason to avoid general anaesthesia in pregnancy. BMJ CaseReports, 10, 1136.

8. ESTS textbook of thoracic surgery. (2014). Medycyna Praktyczna.

9. Toppenberg, K.S., Hill, D.A., \& Miller DP. (1999). Safety of radiographic imaging during pregnancy. Am. Fam. Physician., 59, 1813-1818.

10. VanWinter, J.T., Nichols, F.C. III, Pairolero, P.C., Ney, J.A., \& Ogburn, Jr P.L. (1996). Management of spontaneous pneumothorax during pregnancy: case report and review of the literature. Mayo Clinic Proceedings, 71, 249-252.

11. Leontic, E.A. (1977). Respiratory disease in pregnancy. Medical Clinics of North America, 61 (1), 111-128.
12. Flint, K., Al-Hillawi, A.H., \& Johnson, N.M. (1984). Conservative management of spontaneous pneumothorax. Lancet, 687-688.

13. Kircher, L.T. Jr., \& Swartzel, R.L. (1954). Spontaneous pneumothorax and its treatment. JAMA, 155, 24-29.

14. Kelly, A.M., Loy, J., \& Tsang, A.Y.L. (2006). Estimating the rate of reexpansion of spontaneous pneumothorax by a formula derived from computedtomography volumetry studies. Emerg. Med. J., 23, 780-782.

15. Northfield, T.C. (1971). Oxygen therapy for spontaneous pneumothorax.BMJ, 4, 86-88.

16. Nwaejike, N., Aldam, P., Pulimood, T., Giles, R., Brockelsby, J., Fuld, J., Hughes, J., \& Coonar, A. (2012). A case of recurrent spontaneous pneumothorax during pregnancy treated with videoassisted thoracoscopic surgery. BMJ Case Reports, 10.

17. Sathiyathasan, S., Jeyanthan, K., Furtado, G., \& Hamid, R. (2009). Pneumothorax and pneumomediastinum in pregnancy: a case report. Obstet. Gynecol. Int., 18.

18. Gorospe, L., Puente, S., \& Madrid, C. (2002). Spontaneous pneumothorax during pregnancy. South Med. J., 95, 555-558.

19. Onodera, K., Noda, M., Okadaand, Y., \& Kondo, T. (2013). Awake videothoracoscopic surgery for intractable pneumothorax in pregnancy by using a singleportal plus puncture. Interactive Cardio Vascular and Thoracic Surgery, 17, 438-440.

20. Avital, A., Galante, O., Baron, J., Smoliakov, A., Heimer, D., \& Avnun, L. (2009). Spontaneous pneumothorax in the third trimester of pregnancy. BMJ Case Rep.

21. Atls Student Course Manual: Advanced Trauma Life Support 9th ed. Edition American College of Surgeons; September 1, 2012. 